Personalidade Acadêmica Homenageada:

Augustus B. Cochran III (Agnes Scott College)

\title{
DIREITO EMPRESARIAL X DIREITO À ALIMENTAÇÃO: ALIMENTO TRANSGÊNICO E FOME
}

\section{BUSINESS LAW X RIGHT TO FOOD: TRANSGENIC FOOD AND HUNGER}

VALMIR CÉSAR POZZETTI

Doutor em Biodireito/Direito Ambiental pela Université de Limoges/França. Mestre em Direito do Urbanismo e do Meio Ambiente, pela Université de Limoges, França. Professor Adjunto e Orientador da UFAM. E-mail: v_pozzetti@hotmail.com

\section{MARIE JOAN NASCIMENTO FERREIRA}

Doutoranda em Ciências do Ambiente e Sustentabilidade na Amazônia pela Universidade Federal do Amazonas. E-mail: marie-joan@hotmail.com

\section{MÁRYKA LUCY DA SILVA MENDES}

Discente Especial do Programa de Mestrado em Ciências ambientais e sustentabilidade na Amazônia, da UFAM - Universidade Federal do Amazonas. Email: maryka.mendes12@gmail.com

\section{RESUMO}

A presente pesquisa objetivou apresentar um enfoque paralelo entre a erradicação da fome e o direito humano fundamental à alimentação, como principal necessidade básica de países periféricos, diante dos alimentos transgênicos produzidos. Não se pode olvidar da importância do comércio, ora originado também pelo excedente de 


\section{Personalidade Acadêmica Homenageada:}

\section{Augustus B. Cochran III (Agnes Scott College)}

produção de alimentos, e da livre iniciativa, como economia democrática atrelado ao desenvolvimento sustentável e ao desenvolvimento econômico da agricultura. A metodologia utilizada nesta pesquisa foi o método dialético/dedutivo; quanto aos meios a pesquisa foi a bibliográfica e, quantos aos fins, qualitativa, de forma multidisciplinar, analisando a doutrina, legislação e jurisprudência. A propriedade, ora instrumento integrador para distribuição de terras, através da Reforma Agrária, e a sua inclusão no ordenamento jurídico, visto que o Estado sempre foi o latifundiário principal. A influência da Constituição Federal de 1988 que incluiu como seus fundamentos a dignidade da pessoa humana que consubstancia na erradicação da pobreza e o desenvolvimento nacional, como objetivos fundamentais. Ressaltando, ainda, a livre iniciativa no capítulo da Ordem Econômica e Financeira. Desdobrando tais normas constitucionais, surge a Lei de Biossegurança Nacional. Refletindo, também, a importância da livre iniciativa para o desenvolvimento econômico e eliminação das desigualdades sociais, advertindo a utilização dos alimentos transgênicos, vislumbrando cuidados o meio ambiente natural e suas formas, assim como a saúde do homem. Concluiu-se que a concretização da felicidade do homem só se faz com justiça social. O advento da Biotecnologia com os alimentos transgênicos para salvação da população do pavor da fome que se assolava no mundo, diante da superpopulação. Os perigos da utilização dos alimentos transgênicos pela falta de informação adequada para os consumidores, dos seus efeitos colaterais. Visando, assim, somente o lucro, deixando um desenvolvimento econômico falso, insegurança alimentar e manutenção da pobreza. Deve-se, portanto, alinhar o desenvolvimento econômico e o desenvolvimento sustentável, ora direitos humanos fundamentais. Imperiosa a manutenção da espécie humana, posto que o direito à alimentação é direito fundamental universal.

PALAVRAS-CHAVES: Direito à Alimentação; Alimento Transgênico; Fome; Desenvolvimento Sustentável; Livre Iniciativa. 
Personalidade Acadêmica Homenageada:

Augustus B. Cochran III (Agnes Scott College)

\section{ABSTRACT}

The present research aims to present a parallel approach between the fundamental human right to food, as the main basic need of peripheral countries, in relation to transgenic food produced and the eradication of hunger. One can not forget the importance of trade, which is also caused by surplus food production and free enterprise, as a democratic economy linked to sustainable development and the economic development of agriculture. The methodology used was the dialectical method, based on bibliographical and qualitative research, in a multidisciplinary way, analyzing doctrine and jurisprudence. Ownership, now an integrating instrument for land distribution through Agrarian Reform, and its inclusion in the legal system, since the State has always been the main landowner. The influence of the Federal Constitution of 1988 that included as its foundations the dignity of the human person that consubstantiates in the eradication of poverty and the national development, as fundamental objectives. Emphasis is also placed on free enterprise in the chapter on Economic and Financial Order. Unfolding these constitutional norms, the National Biosafety Law emerges. Also reflecting the importance of free initiative for economic development and elimination of social inequalities, warning of the use of transgenic foods, looking at the natural environment and its forms, as well as human health. It was concluded that the fulfillment of man's happiness is only done with social justice. The advent of biotechnology with transgenic food to save the population from the dread of hunger that was plaguing the world, facing overpopulation. The dangers of the use of transgenic food by the lack of adequate information for consumers, its side effects. Aiming only at the profit, leaving a false economic development, food insecurity and maintenance of poverty. It is therefore necessary to align economic development and sustainable development and sustainable development, and fundamental human rights. The maintenance of the human species is imperative, since the right to food is a universal fundamental right. 
Personalidade Acadêmica Homenageada:

Augustus B. Cochran III (Agnes Scott College)

KEYWORDS: Right to Food; Transgenic Food; Hunger; Sustainable Development; Free Enterprise.

\section{INTRODUÇÃO}

A população do planeta cresce a cada dia, bem como as desigualdades sociais e econômicas. Os países ricos consomem cada vez mais, e seus cidadãos continuam insatisfeitos, enquanto que os países pobres amarguram a fome e as demais desigualdades.

O objetivo dessa pesquisa é o de analisar a legislação pertinente, os fatos sociais e verificar se a transgênia pode continuar a se utilizada em larga escala.o

O direito à alimentação é uma necessidade básica dos habitantes dos países subdesenvolvidos, devendo seus governantes realizar esforços para que esse direito seja incluído e assegurado como direito humano fundamental nas principais constituições desses países, como forma de eliminar a fome.

Os alimentos transgênicos, por sua vez, trazem consigo a carga genética das técnicas de biotecnologia, com melhoramentos. Surgiram com a promessa de que iriam eliminar a fome no planeta; entretanto, não conseguiram cumprir a promessa vez que a fome ainda se faz sentir de forma contundente no planeta; logo os alimentos transgênicos não cumpriram o que prometeram.

Além de não eliminar a fome no planeta, ainda trouxeram uma carga negativa: aumentou-se a poluição em virtude dos agrotóxicos e aumentaram-se o número de doenças, resultado da modificação genética e uso de agrotóxicos.

A livre iniciativa como pressuposto para o desenvolvimento nacional e a eliminação das desigualdades sociais, diante da função social das empresas, ora comércio. 
Personalidade Acadêmica Homenageada:

Augustus B. Cochran III (Agnes Scott College)

A abordagem temática contextualizou se a justificativa da utilização do referido alimento como exterminador da fome, o direito à livre concorrência como economia democrática, se alia ao desenvolvimento sustentável.

A Constituição Federal Brasileira, por sua vez, observa a dignidade da pessoa humana e os valores sociais do trabalho e da livre iniciativa, como fundamentos do Estado Democrático de Direito, no artigo 10, incisos III e IV. Ressaltando-se, ainda, seus objetivos fundamentais de garantir o desenvolvimento nacional e erradicar a pobreza, ora dispostos no artigo $3^{\circ}$, incisos II e III.

A problemática que movimentou essa pesquisa foi: de que forma assegurar ao habitante do planeta terra, uma alimentação saudável, com conservação ambiental equilibrada?

Neste sentido, buscar-se-á demonstrar o paralelo entre a necessidade do desenvolvimento econômico e a eliminação da forme, através dos alimentos transgênicos.

Dessa forma, a pesquisa se justifica, tendo em vista que a fome não foi eliminada, o problema persistiu, além de outros que sobrevieram do uso e plantio de sementes transgênicas. Restando, assim, imprescindível a pesquisa para demonstrar os riscos para o desenvolvimento sustentável.

\section{OBJETIVOS}

O presente estudo objetiva demonstrar as consequências da utilização de alimentos transgênicos, considerando o marketing utilizado como forma de eliminação da fome e desenvolvimento econômico para a agricultura, colocando-se de lado o meio ambiente e principalmente, o desenvolvimento sustentável.

Analisar os fundamentos empregados para tanto, juntamente com a Constituição Federal do Brasil e os direitos humanos, suas diferenças e benefícios. 
Personalidade Acadêmica Homenageada:

Augustus B. Cochran III (Agnes Scott College)

\section{METODOLOGIA}

Como metodologia científica será utilizado o método dedutivo; quanto aos meios a pesquisa será a bibliográfica, com o uso da legislação, jurisprudência doutrina e, quanto aos fins a pesquisa será a qualitativa.

\section{RESULTADOS}

O alimento encontra-se acessível ao homem desde os primórdios para sua subsistência, mesmo sem poder aquisitivo ou sem terra. Além disso, o anseio de erradicar a pobreza não tornou-se realidade, através do excedente global de alimentos, pois não se traduz em segurança alimentar, bem como a falta de políticas públicas para realizar sua melhor distribuição.

No Brasil, não foi diferente, como acentua Abreu et tal (2001):

(...) a fome medida pelas reservas energéticas da população no Brasil tem incidência restrita no País, afetando de forma clara apenas a população rural do nordeste, ainda assim em grau leve e moderado de acordo com padrões internacionais. A população urbana de todo o País apresenta-se protegida da fome, incluindo as que vivem nas regiões norte e nordeste e a população rural do País.

Desde a Coroa Portuguesa, o Estado é o latifundiário do território brasileiro, inviabilizando a exploração da terra, bem como a reforma agrária. Como salienta Pozzetti e Ferreira (2017, p. 485):

Com a independência do Brasil, as terras não particulares passaram da coroa portuguesa para a coroa brasileira e se tornaram patrimônio do imperador, que passou a ser o grande latifundiário do território brasileiro. Após a proclamação da república, as terras passaram da coroa portuguesa à União Federal e a CF/1891, em seu artigo 64 transferiu todas as terras 
Personalidade Acadêmica Homenageada:

Augustus B. Cochran III (Agnes Scott College)

devolutas - que não implicavam em colocar em risco a segurança nacional ao patrimônio dos estados.

A justiça social foi traçada pela luta dos excluídos da terra juntamente com a igreja católica que resultou na inclusão da reforma agrária na Constituição Federal de 1988, o que possibilitou felicidade, dignidade ao possuir uma propriedade. Assim dispõe Pozzetti e Ferreira (2017, p. 486):

A propriedade rural é a responsável pelo o alimento diário, seja ele oriundo da agricultura ou pecuária, por exemplo, mas ao mesmo tempo desprezada por muitos, diante da falta de valorização do produtor rural, bem como dos bens produzidos por ele.

Boff (2016, p.53) também demonstra o desperdício das propriedades da Terra:

\begin{abstract}
Já tocamos nos limites da Terra. Está ocorrendo a assim chamada sobrecarga da Terra (Earth Overshoot Day). A pegada ecológica humana (quanto de bens e serviços precisamos para viver) foi ultrapassada. As reservas da Terra estão se acabando e já precisamos de mais de um planeta para atender as nossas necessidades, além daquelas da grande comunidade de vida (fauna, flora, micro-organismos). Como pode ser feliz a Terra em semelhante situação?
\end{abstract}

A felicidade não se compra, nem se consegue com potes de ouro. A felicidade encontra-se todos os dias, quando vivemos em harmonia com o próprio homem e a Terra, consolidada pelo nosso Meio Ambiente, no seu conceito literal e todas as suas formas.

Com o advento dos excedentes na produção de alimentos, surge o escambo, como forma de troca, que facilitou distribuição de alimento e, assim, intensificou o comércio.

A circulação de bens proporcionou a organização da atividade econômica. No Brasil, o surgimento da Teoria do Comércio pelos franceses, ora utilizada no 
Personalidade Acadêmica Homenageada:

Augustus B. Cochran III (Agnes Scott College)

Código Comercial de 1850. Mais tarde, alocada como Teoria da Empresa, fundamentada pelos italianos que inspirou o Código Civil de 2002.

Com o advento da Constituição Federal de 1988 surge a função social da empresa, tornando-se importante na economia do Brasil, bem como no mundo, diante da Globalização Neoliberal. No mesmo contexto, Diniz (2018) retrata:

A empresa (atividade econômica organizada) é o centro da economia democratizada, tendo por base a governança corporativa, a produção e a circulação de bens e serviços, beneficiando empresário, empregados, sociedade de consumo, e por diretriz os princípios constitucionais (CE, art. 170, I a IX): soberania nacional, propriedade privada, função social da propriedade, livre concorrência, defesa do consumidor e do meio ambiente, redução de desigualdades regionais e sociais, busca do pleno emprego, tratamento favorecido para as empresas de pequeno porte, constituídas e sediadas no Brasil. A empresa tem responsabilidade social e desempenha uma importante função sócio-econômica, sendo elemento de paz social e solidariedade constituindo um instrumento de política social e de promoção da justiça social. Sua responsabilidade social a impulsiona a propiciar, com sua atividade econômica, comunicação mais aberta com seus colaboradores e com a coletividade, melhores condições sociais, garantindo sua sobrevivência no mercado globalizado, por ser fator decisivo no seu crescimento, visto que ganhará o respeito de seus colaboradores e consumidores e provocará sua inserção na sociedade.

Com a necessidade proeminente no mundo de erradicar a fome, surgiram vários mecanismos para tanto. Muitos não tiveram êxito e outros ficaram apenas no papel, sem sua implementação.

Todavia, a biotecnologia, como assinala Teixeira (2016), já era utilizada, "sua origem pode ter ocorrido há mais de seis mil anos, a partir dos relatos de que os microorganismos eram usados nos processos fermentativos para produção da cerveja e do pão".

Surge, então, a transgenia, derivado dos estudos da genética, na metade do século XIX, a produção de OGMS (Organismos Geneticamente Modificados) e seus derivados. Espalhou-se mundialmente e tornou-se o assunto relevante nos principais setores e sociedades. Pozzetti (2014) ressalta: 
Personalidade Acadêmica Homenageada:

Augustus B. Cochran III (Agnes Scott College)

\begin{abstract}
Uma das principais polêmicas é a que diz respeito aos Alimentos Transgênicos, que surgiram com o "objetivo de matar a fome do mundo e oferecer alimentos seguros e em quantidade necessária à demanda da população do planeta, que cresce". Não se sabe ainda se, com a utilização dos transgênicos, preservar-se-á a qualidade alimentar e conservar-se-á os recursos genéticos; pois a ciência ainda não provou, cientificamente, que esses alimentos são saudáveis e que não trarão, de futuro, prejuízos à saúde do consumidor.
\end{abstract}

Ora, como questionar a produção os OGMS, se eles vieram para salvar o mundo, desde a erradicação da pobreza até a preservação do meio ambiente, bem como a convivência com o desenvolvimento sustentável.

Aliando-se ao pensamento de Pozzetti, já citado, nota-se o capitalismo gerenciando o desenvolvimento econômico, com a utilização dos OGMS, para implementar a produtividade e alcançar todas as populações do mundo, retirando o pavor globalizado da fome que assolaria o planeta, diante da superpopulação que se aproxima.

Não se pode olvidar, do direito à livre concorrência e sua função social para redução das desigualdades sociais e manutenção da soberania de um povo. Ademais traria riqueza também para o país que abraçasse tal ilusão, como indica Teixeira (2016, p. 33):

(...) As empresas de Biotecnologia, vendendo esta informação, iniciaram campanhas científicas alegando que os alimentos transgênicos acabariam com o problema da fome no planeta e prometeram que esses alimentos, modificados geneticamente, teriam maior teor nutritivo, seriam produzidos com maior rapidez e rentabilidade e a um preço baixo, menor que os alimentos orgânicos. Entretanto, até o presente momento, nenhuma dessas promessas foram cumpridas.

Pozzetti (2014, p. 211) também adverte que "as pessoas não são informadas sobre o efeito colateral dos alimentos transgênicos, mesmo porque ainda não se sabe quais seriam estes".

Diante do exposto, traz-se à tona, a ilusão de promessas miraculosas, irresponsáveis, apenas com intuito de lucro, de um desenvolvimento econômico 
Personalidade Acadêmica Homenageada:

Augustus B. Cochran III (Agnes Scott College)

falso, da insegurança da aplicação do direito fundamental à alimentação, e consequentemente, da manutenção da pobreza.

\section{CONSIDERAÇÕES FINAIS}

A problemática que movimentou essa pesquisa foi a de se verificar de que forma se poderá, diante das incertezas trazidas pela manipulação genética assegurar ao habitante do planeta terra, uma alimentação saudável, com conservação ambiental equilibrada.

Os objetivos da pesquisa foram cumpridos à medida em que se analisou a legislação, as fontes doutrinárias, chegando a um resultado qualitativo da pesquisa.

No que tange ao desenvolvido de pesquisas relacionadas aos alimentos transgênicos, verificou-se que, principalmente no Brasil, é imprescindível a aplicação do Princípio da Precaução, que está contido, explicitamente, na Lei de Biossegurança Nacional - Lei no 11.105/2005.

Deve-se ater às questões éticas e humanitárias com o pronunciamento e coordenação das partes envolvidas, como os agricultores, as Instituições de Pesquisas Cientificas, os governos, as sociedades civis e os movimentos sociais, para refletir sobre a soberania alimentar, a biodiversidade e os direitos humanos.

Concluiu-se que, no âmbito da produção de alimentos transgênicos, não poderá haver retrocesso no âmbito dos direitos humanos conquistados, tais como direito à saúde, à dignidade e ao meio ambiente equilibrado; que os Estados deve exigir pesquisas mais profundas no sentido de promover alimentos para todos, com qualidade e a preço acessível, com distribuição de renda, assegurando à todos os produtores de alimentos a liberdade e independência para a produção de alimentos que gerem saúde os consumidores. 
Personalidade Acadêmica Homenageada:

Augustus B. Cochran III (Agnes Scott College)

\section{REFERÊNCIAS}

ABREU, Edeli Simioni et tal. ALIMENTAÇÃO MUNDIAL - uma reflexão sobre a história. Saúde e Sociedade. Faculdade de Saúde Pública. Universidade de São Paulo. Associação Paulista de Saúde Pública. São Paulo, 2001.

BRASIL. Constituição da República Federativa do. Congresso Nacional. Brasília: 1988.

. Politica Nacional do Meio Ambiente

DINIZ, Maria Helena. IMPORTÂNCIA DA FUNÇÃO SOCIAL DA EMPRESA. Revista Jurídica - Unicuritiba. Revista Jurídica vol. 02, n. 51, Curitiba, pp.387-412. DOI: 10.6084/m9.figshare.6835007.

POZZETTI, Valmir César. ALIMENTOS TRANSGÊNICOS E O DIREITO DO CONSUMIDOR À INFORMAÇÃO. Revista Jurídica - Unicuritiba - vol.03, n.36, Curitiba, 2014. ISSN: 2316-753x

; FERREIRA, Marie Joan Nascimento. DIREITO DO ESTRANGEIRO, IMIGRANTE OU REFUGIADO, Á PROPRIEDADE RURAL, NO BRASIL. Revista Jurídica - Unicuritiba - vol.03, n.48, Curitiba, 2017, pp.482-503. DOI:10.6084/m9.figshare.5313667.

TEIXEIRA JÚNIOR, Juarez Ribas. BIOSSEGURANÇA E SOBERANIA NACIONAL. Dissertação. Orientador: Fernando Gustavo Knoerr. Mestrado em Direito Empresarial e Cidadania. Centro Universitário Curitiba. Curitiba, 2016. 